\title{
New Sustainable Market Opportunities for Surplus Food: A Food System-Sensitive Methodology (FSSM)
}

\author{
Thomas H. O'Donnell'1, Jonathan Deutsch ${ }^{2}$, Cathy Yungmann ${ }^{3}$, Alexandra Zeitz ${ }^{4}$, \\ Solomon H. Katz ${ }^{5}$ \\ ${ }^{1}$ Land and Chemicals Division, U. S. Environmental Protection Agency, N.A.H.E., Region 3, Philadelphia, USA \\ ${ }^{2}$ Department of Culinary Arts and Food Science, Center for Hospitality and Sport Management, Drexel \\ University, Philadelphia, USA \\ ${ }^{3}$ Department of Communication, Cabrini College, Radnor, USA \\ ${ }^{4}$ Drexel Food Lab, Center for Hospitality and Sport Management, Drexel University, Philadelphia, USA \\ ${ }^{5}$ Krogman Center for Research in Child Growth and Development, University of Pennsylvania, CEO World Food \\ Forum, Philadelphia, USA \\ Email: odonnell.tom@epa.gov, jdeutsch@drexel.edu, cathy.yungmann@cabrini.edu, atz25@drexel.edu, \\ skatz2001@aol.com
}

Received 21 May 2015; accepted 21 July 2015; published 24 July 2015

Copyright (C) 2015 by authors and Scientific Research Publishing Inc.

This work is licensed under the Creative Commons Attribution International License (CC BY).

http://creativecommons.org/licenses/by/4.0/

(c) (i) Open Access

\section{Abstract}

An important way to address global food security is to make better use of the food already produced. Since at least one third of global food is wasted before consumption, there are enormous incentives to cut this waste and create a more sustainable food system. This paper focuses upon saving food loss at the supermarket level in the US and channeling this food stream in new and efficient ways to those in hunger. A more comprehensive Food System-Sensitive Methodology has been used to pilot and evaluate a surplus food management program that diverts culled fresh fruits and vegetables from grocery stores that would otherwise be disposed of in landfills. Instead, produce is processed for donation or for new businesses. Nearly 35,000 pounds of produce was culled from a grocery store chain in Philadelphia. Twenty-five percent of this was not suitable for culinary uses, ten percent consisted of relatively small quantities of food that did not warrant further research, and about 33 percent is suitable for use at area food shelters and pantries. An experimental sample taken from the remaining 15,000 pounds was used for recipe research and development for diversion to new commercial enterprises. We analyzed a scenario where a supermarket receives $\$ 0.25$ per pound for culled produce, generating about $\$ 8700$ dollars in average monthly revenue while eliminating disposal costs. New commercial possibilities for the unused food were then explored. The scenario included community-based enterprises that could process the produce into value-added products that could be wholesaled back to the store at sufficient 
profits to support 2 - 4 community employees. Extrapolating these results to the approximately 38,000 large supermarkets in the United States suggests that much of the $1,100,000,000$ pounds of produce that is currently sent to landfills can be repurposed. If diverted to new foods each of the 46.1 million SNAP recipients could figuratively receive an equivalent of 24 pounds of fruit and vegetable products per annum. This initial analysis suggests that repurposing surplus produce from supermarket discards can have significant beneficial outcomes for new food markets and the environment.

\section{Keywords}

Market, Sustainability, Food, Waste, Hunger

\section{Introduction}

The global food security crisis of 2008-09 led to deep and growing concerns about how to increase food productivity sustainably in the presence of worsening climate change and continued rapid population growth [1]. Although these concerns about raising (and maintaining) food production continue today, other FAO developments to make better use of the foods already produced by reducing food waste began in 2011 with the FAO [2] report entitled "Global Food Losses and Waste: Extent, Causes and Prevention". This report identified opportunities for increasing existing food availability without increases in the economic and environmental costs (including for increasingly scarce water) of adding new sources of food production. This and subsequent reports [3] [4] indicate that about one third of all global food produced is lost along the food chain (harvest, transport, storage, processing, marketing, and at restaurants and home) before consumption.

While sources of food waste occur throughout the food chain, their distribution among the nations varies with the levels of economic development, with the poorer countries having the greatest loss at harvest and storage and the richer countries like the US with losses at the marketing and restaurant and home consumption levels. In this regard, some estimates [5] indicate that the US has an overall food waste level of about $40 \%$, which makes it one of the most wasteful in the world. Moreover, food loss in the US is highest with fresh produce and fruit, with slightly over $49 \%$ [6] routinely culled at the supermarkets to remove any blemished and/or ripened products from the shelves. Although this food is mostly still perfectly edible, relatively little of it is routinely given away to food pantries. Instead, this "waste" food is deposited in dumpsters and then transported and dumped into landfills, with only a small fraction sent to composters. The substantial economic cost of this transport and dumping are borne by the supermarkets and passed on to its customers in higher prices. However, the negative external costs of the high levels of methane, a greenhouse gas that is approximately 23 times more potent than $\mathrm{CO}_{2}$, are borne by the public.

Because of the high level of this type of food waste and the nutrient advantages of fresh produce and fruit compared to the highly processed foods typically consumed in poor urban household diets, produce and fruit culled at the supermarket is a highly desirable source to divert from waste streams to new food resource streams. Moreover, the EPA has also identified this food diversion as an ideal means to reduce methane produced from dumping these foods at landfills. In addition, this food could be a valuable caloric and nutrient dietary resource for people in hunger especially in urban areas that have a high concentration of supermarkets. Since not all of this food identified as edible can be immediately and effectively used by food pantries, there may be significant economic opportunities to cook and prepare any food excess into new processed food products that can be sold or redistributed within the recipient communities.

All of these new and/or improved uses of these previously wasted food resources require a wide range of knowledge and practical experience to provide substantial reductions in waste. Hence the purpose of this paper/ study was to form and integrate a team of public and private organizations (Table 1) with special competencies to test the feasibility and sustainability of diverting supermarket (and soon local farm) culled fruit and produce into the social and business food streams in order to reduce food waste and feed people in hunger.

In addition, these specialists formed a working group to determine the degree to which surplus food cost savings and waste prevention can be integrated into the existing food system in ways that reduce hunger and increase the 
Table 1. Organizations and specialists participating in the urban model for surplus food recovery.

\begin{tabular}{llc}
\hline Institutions \& Agencies & Organizations & Specialists \\
\hline & Brown's Super Stores & Local Farmers \\
Drexel University & Giant-Ahold Grocery Stores & Academic specialists: \\
University of Pennsylvania & University City District & Food Anthropology, Environmental \\
City of Philadelphia & The Enterprise Center & Science, Culinary Arts, Food Science \& \\
US Environmental Protection Agency & Center for Culinary Enterprise & Nutrition, Food Safety, Food Product \\
US Department of Agriculture & Hunger Relief Organizations: & RD, Public Health \\
Delaware Valley Regional Planning Commission & Philabundance, City Team, & \\
& My Brothers House & \\
\hline
\end{tabular}

economic potentials of the new food resource streams. Multiple field, lab, and research tools have yielded an initial heuristic model that can be used to understand and test the steps necessary to enable new businesses to safely reduce food waste, create new business and job opportunities, reduce hunger, and enhance overall sustainable food management. This report explains the initial applied research that is underway to divert and use surplus supermarket produce as inputs to food processing for restaurant menu items and for new food products. Local farm produce would apply in many of the same ways. Our objective is to demonstrate that fresh, ripe fruits and vegetables that grocers remove from sale primarily for cosmetic or packaging reasons can become a large, local source of low cost inputs for new and sustainable food production.

\section{Project Site and Case Study}

University City is an approximately 2.4 square mile neighborhood in west Philadelphia that houses some of the best universities, hospitals, and transportation hubs in the City. It also is home to a large population of low income individuals who are supported by public and non-profit health and hunger relief organizations. Figure 1 shows the boundaries of University City and the Philadelphia Promise Zone designated by the federal government [7] as an area for investment focus for quality of life revitalization [8]. The Urban Model for Surplus Food Recovery, a Region 3 EPA pilot, was initially launched in University City but expanded in collaboration with Drexel University once the Promise Zone designation was awarded.

University City lies within three ZIP codes (19104, 19139, and 19143). Based on the most current census data, 88,716 residents are food insecure [9]. These people then are in need of a consistent supply of nutritious food but only have limited resources to buy them. Matching these food needs and supply limitations is one of the principle social drivers to our evaluation and testing of the degree to which surplus fresh foods from supermarkets can meet pricing and nutrient needs of lower income populations in this pilot area and similar ones throughout the United States where 49.1 million people report being food insecure in 2013 [10].

\section{Procedure}

Members of the United States Environmental Protection Agency’s (EPA), Region 3, Food Recovery Challenge (FRC), set out to facilitate diversion of food from landfills utilizing a community-based approach to food recovery. The Agency's Food Recovery Hierarchy Figure 2 served as a guide for targeting diversion options. The hierarchy is tiered from food waste prevention the most preferred to landfill the least preferred. The initial goals were to develop a replicable, scalable Surplus Food Recovery Model in an urban setting to promote the diversion of food from solid waste landfills by encouraging and supporting composting and food donation to people in need in potential Environmental Justice communities [11]. More recently with new knowledge and experience, efforts have evolved to embrace source waste reduction \& prevention by integrating sustainability planning elements of economics, social justice, and environmental improvement with the hierarchy.

During the initial stages of the project, a planning study was completed to identify key stakeholders, and form an advisory panel, to engage the community and determine the feasibility of such a project. Advisory Panel members included the Delaware Valley Planning Commission (DVRPC), Organic Diversion (local composter), Philabundance (local food bank), and the Bucks County Foodshed Alliance (local food system NGO). The stakeholder group presented the concept of the project on September 2012 to the DVRPC Food Stakeholder Committee. The purpose of this meeting was to convene and receive input from greater Philadelphia area food stakeholders on the concept and details of implementing such a project. Stakeholders determined at that time 


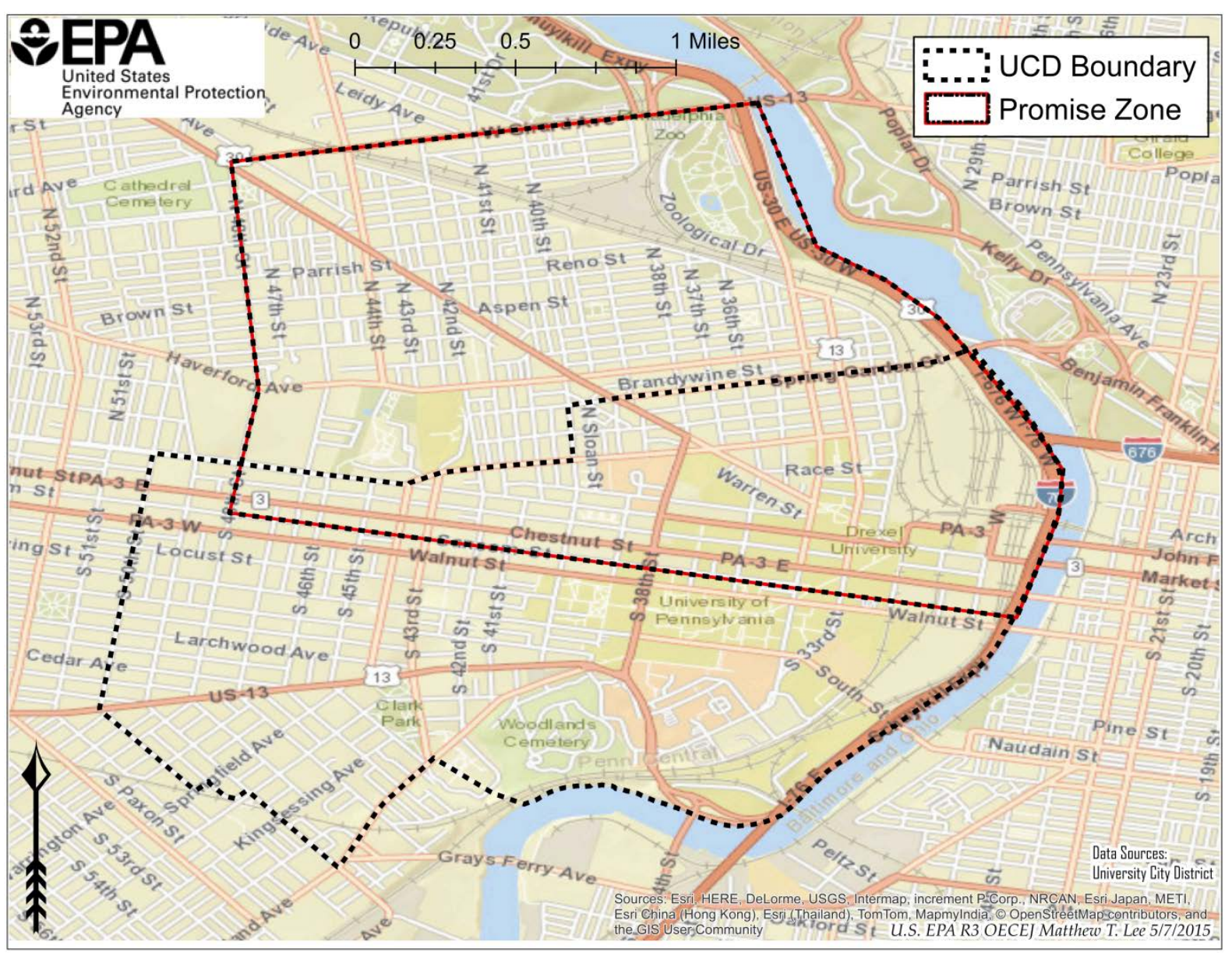

Figure 1. University City neighborhood and federally designated Promise Zone in west Philadelphia.

\section{\&EPA Food Recovery Hierarchy}

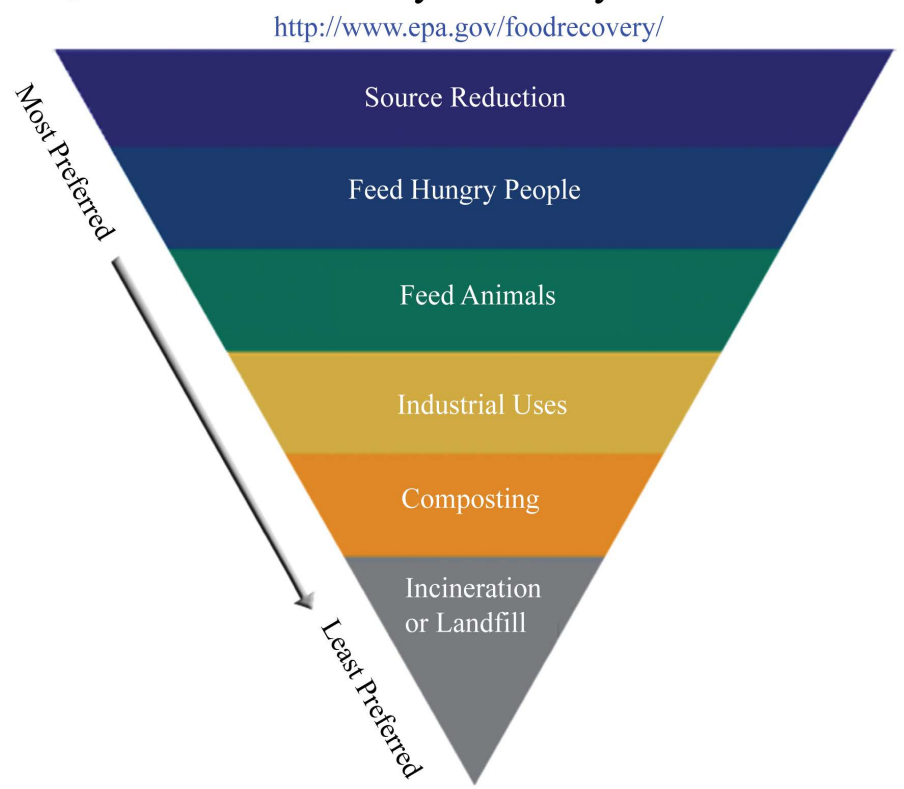

Figure 2. EPA food recovery hierarchy. 
that there was a need to develop an urban option for food recovery since the City of Philadelphia was home to about $21 \%$ food insecure people. Businesses and Institutions were receptive to the project and willing to participate.

Utilizing a food Life Cycle Analysis (LCA) approach for the entire Philadelphia urban area, a geographic information system (GIS) database tool was developed to identify the largest generators of surplus-food (hospitals, grocery, venues, universities, hospitality, etc.) and possible receptors of surplus-food (i.e. community gardens, food banks, composting facilities, etc.). The concept of using surplus food for new products or as inputs to restaurants had not emerged at these early stages of the project. The west Philadelphia, University City neighborhood was selected to implement the model based in part on a rich diversity of surplus-food generators, local composting/donation facilities, a range of community gardens and urban farms, and a strong economic development organization. The University City District, willing to lead the project as a pilot to learn how to accomplish and expand upon the food waste diversion goals, launched the community Food Recycling Project in April 2013.

In March 2014, the EPA in partnership with Drexel University's new Food Lab and Brown's Super Stores, a Philadelphia area supermarket chain, began to explore methods of transforming culled, fresh produce from the store into various fruit and vegetable product and meal items using creative recipes. The Food Lab, working with local community shelters and food cupboards learned that much of the donated fresh produce was so fragile that it often was offered and not taken; hence, diminishing the donation option. The concept of using culinary research and development to produce wholesome desirable foods free of any cosmetic issues evolved from these observations and the partnership. A new vision emerged, one that recognized the possibility of avoiding food waste while using ripe nutritious surplus foods as inputs to new food products [12]. A working hypothesis also emerged that suggested that surplus food could be purchased at a reduced cost; thereby, allowing products to be developed that could compete in the marketplace with highly processed foods that are so popular in underserved Philadelphia neighborhoods. Initial reports of this research were presented at various conferences while being popularized in blogposts [13] [14] and multi-media news organizations [15]. The Federal Executive Board recognized the project as an example of Outstanding Public Service in May, 2014 [16]. In November, 2014 the Administrator of the USEPA visited the Food Lab to laud the partners who were working to optimize the food transformation program [17].

In the early months of 2015, the Food Lab and partners began evaluating local farm "seconds" for the same purpose, working with The Enterprise Center and Center for Culinary Enterprise to pilot new food products for sale into the local markets. Local experts were also examining how this surplus food could become cost effective inputs into a local community restaurant. The Food Lab's research related to the use of local farm products for nutritious, cost effective food options has been funded by the United States Department of Agriculture, Local Foods Promotion Program starting in October 2014 as a means of enhancing community well-being in the west Philadelphia Promise Zone. As the Food System-Sensitive Methodology (FSSM) expands reaching more sources of surplus food and more partners, the likelihood that this sustainable food system model can be used and adjusted by other cities and developed countries with similar food waste losses at the retail supermarket and retail food delivery industry levels should increase.

\section{Results}

The food research and development specialists from Drexel University Culinary Arts and Food Science program are collaborating with Brown's Super Stores in Philadelphia to experiment with produce discards for the purpose of recipe and food product development. In April 2015, the 11 stores in the brand donated 68,039 pounds of food, of which $51.25 \%$ (34,870 pounds) was fresh fruits and vegetables. These products are a particular challenge due to their perishability. While meats, for example, are easily frozen before their sell-by day, kept in cold-storage and distributed to be defrosted and cooked by a social-service food provider, the same cannot be as easily done with produce.

The Drexel Food Lab's initial and on-going 2015 surveys of discarded produce found that approximately 25\% was unusable/trim such as moldy strawberries, brown greens and bruised apples. Eliminating these components from the starting product weight left 26,152 pounds that was still useful for development (Figure 3). About 10\% of the produce received is perfectly sound but specialty/unusual and not sufficient in quantity for production. For example, prickly pear cactus, kumquats, and avocados may be scattered in the mix of large quantities of sweet potatoes or kale. That reduced the practical yield to 22,665 pounds. By observation, if this remaining yield is 


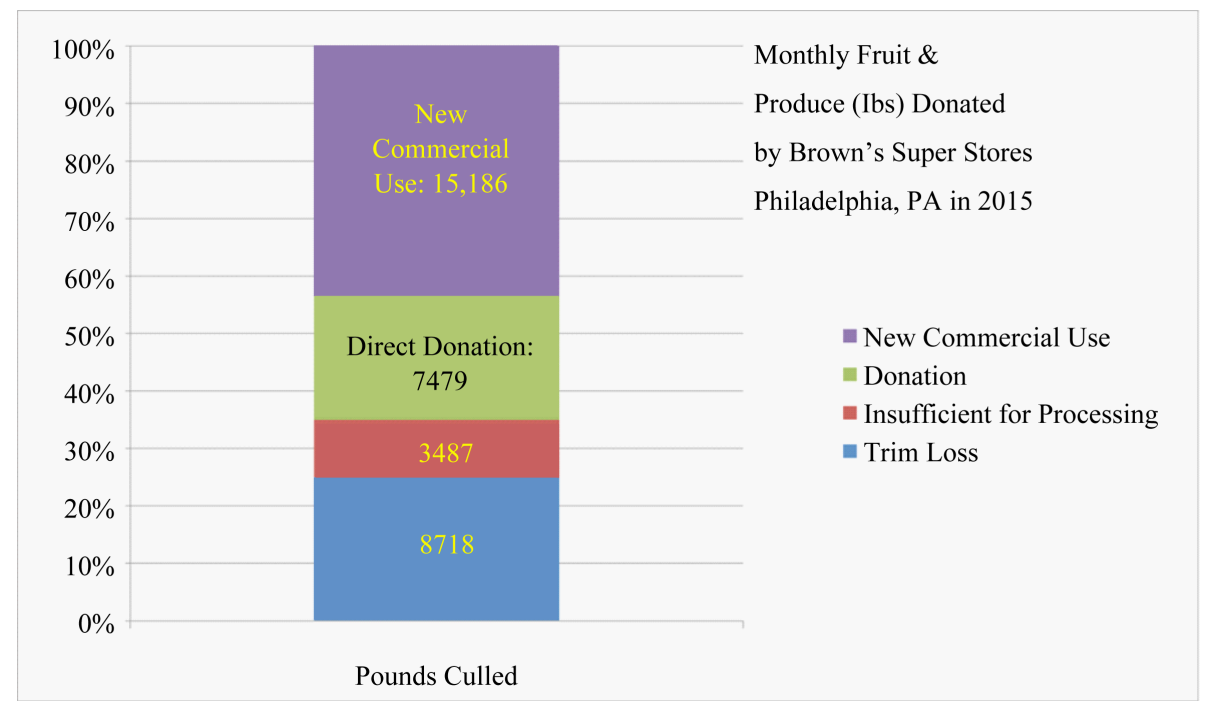

Figure 3. Monthly produce donated by Brown’s Super Stores.

served directly at a soup kitchen or shelter, fresh produce such as apples, baby carrot sticks, bananas, and oranges has about a 33\% uptake. The remainder monthly amount, 15,185 pounds, was surplus food that could be used for new product development or prepared at a restaurant for retail customers. That amount of food is the starting base line that was used for thinking about new business opportunities and how creative social entrepreneurs can envision new products and solutions to the food waste challenge.

Although the sample pool is only one month from a single 11 store chain, small relative to the amount of produce available for donation or product development throughout the year, and the sampling and analysis research is new, several preliminary results are available. The current Drexel Food Lab, sustainable-market working model based on surplus food inputs from supermarkets is to purchase surplus food at a deep discount; for example, $\$ 0.25$ per pound or $\$ 8717$ in the example above. While not much revenue for a supermarket, this would be an additional revenue stream for what had formerly been a disposal expense. Continuing with this possible scenario, a social enterprise of community residents would process that surplus produce into value-added food products such as veggie chips, jams, smoothie bases and other products. These value-added products can then be wholesaled back to the same supermarket or other community-based retailers for $\$ 2.00$ per pound. Accounting for the cost of added ingredients, labor and profit, this would generate $\$ 52,304$ in monthly revenue (starting with $65 \%$ of monthly donated produce multiplied by two dollars per pound), and supporting two to four employees in new jobs at a family wage. These products can then be retailed at $\$ 3.99$, generating $\$ 90,433$ in monthly gross revenue and $\$ 38,129$ after cost of goods sold. The scalable economic, social, and environmental opportunities are potentially substantial.

\section{Discussion}

The life cycle of food loss follows the same path as food for human consumption except where unused food is disposed, given to animals or donated to people (Figure 4). Losses begin at the farm where on average $20 \%$ of produce is not harvested or rejected during processing. Farmers will not pay to pick, sort, package or ship product that will not likely meet customer demands for quality and quantity. The National Resources Defense Council [18], estimated that 80 percent of fruits and vegetables are approved for shipment to food processers. An additional four percent of this fragile food is lost on the way to supermarkets, which is actually one of the most efficient steps in the life cycle. Discards of all food waste from supermarkets in the United States are high, $21 \%$ by some estimates [19], largely because of the demand on the part of the consumer for "picture perfect" produce. Produce that slips past the ideal qualitative appearance standards are removed. Most of the discards still go the landfill although the amount of food going to donation, estimated by the Food Waste Reduction Alliance at about 9\%, is on the rise [20]. Significant amounts of food waste are also used for composting, animal feed and biofuels. Even with slight bruising or discoloration, these foods are ripening and often achieving the highest 


\section{Life Cycle of Supermarket Produce Discards}

Enhanced by New Methods for Waste Prevention \& Healthier Food

Products. Numbers refer to percentage of the indicated flow.

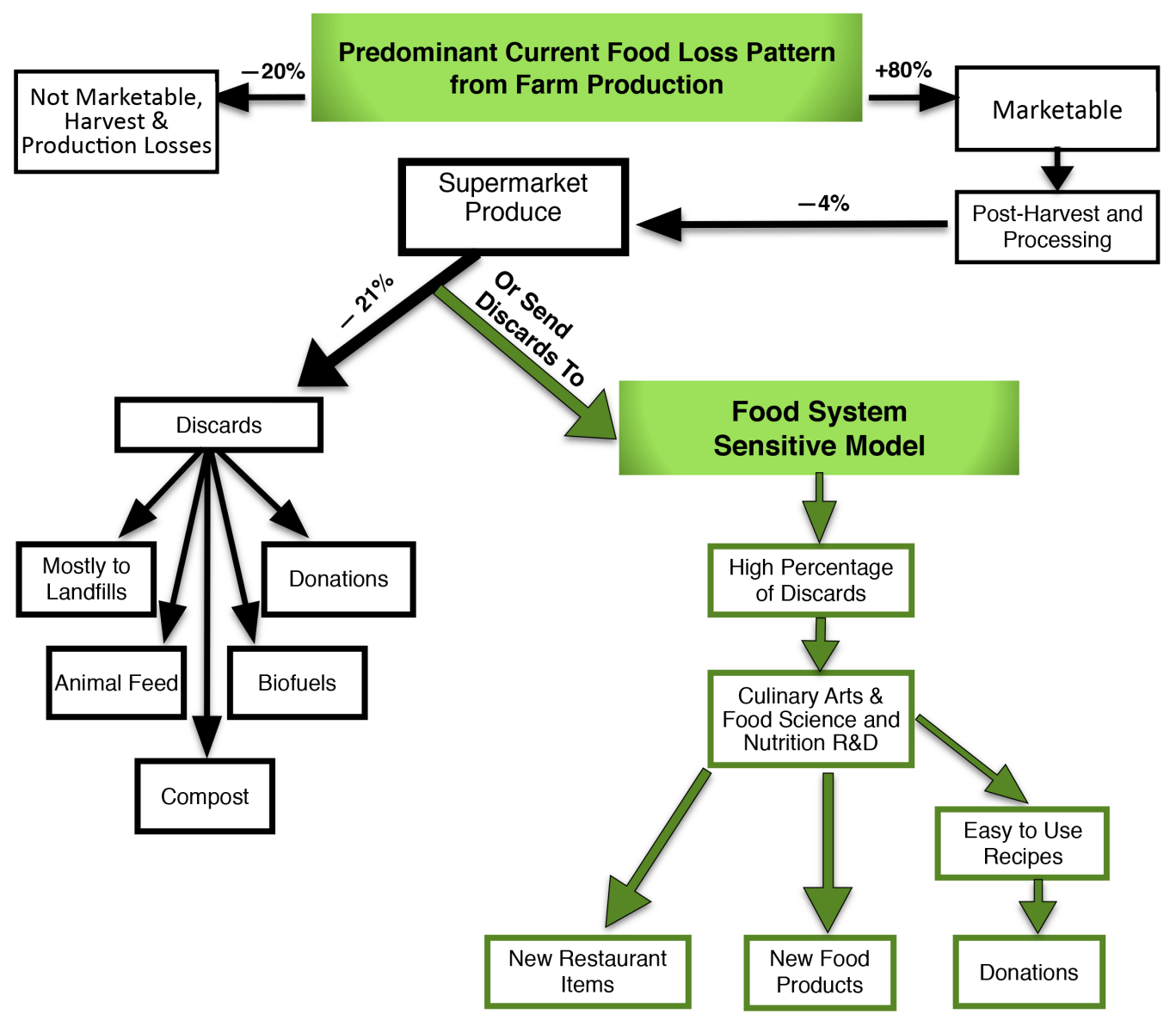

Figure 4. Life cycle of supermarket produce discards.

taste quality that they will have [12]. Viewed in this way, discards become a preferred choice for many culinary purposes; hence, for value as new food products or cuisine.

The use of these produce discards as inputs to new food products using tools of the emerging FSSM is also illustrated in Figure 4 as an enhancement to current surplus food management. Using the Brown's Super Stores data as a general guide, $75 \%$ of this produce should stay in the food chain through donations or as new products because it is not trim loss or spoiled.

The EPA reported that the amount of food that was sent to landfills in 2012 decreased for the first time in history by $0.99 \%$ [6]. Although small, this may be the beginning of a new trend attributable to the efforts of many private and public organizations and individuals. Regardless, EPA also reported that 34.69 million tons of food still went to municipal landfills as waste, of which $49.2 \%$ or 17.03 million tons was fruits and vegetables [21]. Much of that food can be diverted to beneficial use if the technology, innovation, and will to do so is in effect.

The Agency also reported on the types of foods that were wasted in 2010. Figure 5 shows the amount of the most frequently found fruits and vegetables in the solid waste stream. Approximately half of these items come from the grocery store restaurant and food service sectors [21]. If even $10 \%$ of this food was diverted to good use the environment, economic system, and community health systems stand to be significant beneficiaries. All of these produce categories are within the sampling pool used by Brown's Super Stores and the Drexel Food Lab and represent foods that are available for new product development and/or donation to people in need. Food 


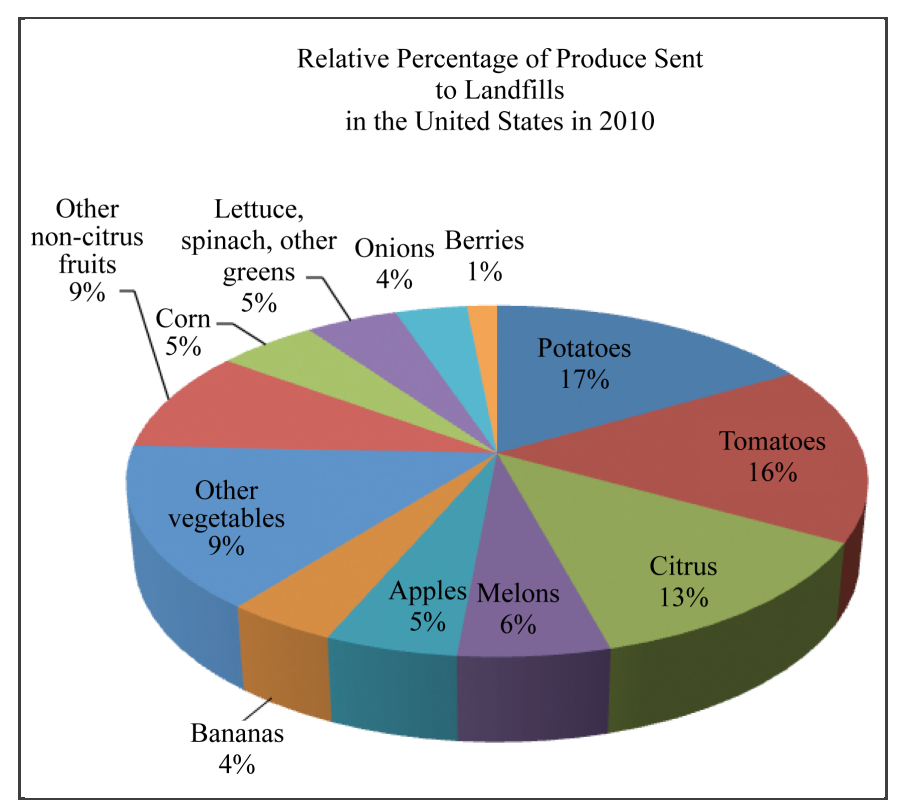

Figure 5. Produce sent to landfills.

loss data from a single grocery store in Philadelphia, PA and from national surveys of food lost as landfill waste is consistent; immense amounts of usable fresh, wholesome produce is disposed of daily from supermarkets.

The Food Marketing Institute [22] reports that fresh fruits and vegetables are sold from 37,716 large supermarkets in the United States (stores with more than \$2,000,000 in sales). The thought of trying to access this vast number of distribution points seems daunting but in many areas sufficient sources are concentrated to consider real processing opportunities. Brown's Super Stores has provided 2014 data on the amount of fruits and vegetables that they discarded from all of their 11 stores. A total of 325,729 pounds was set aside for donations or composting. These were food items that were available to customers, typically discarded for cosmetic reasons, or to open display space for new products with longer available labelling dates as is customary in supermarkets. Applying FSSM using the Drexel Food Lab's estimates of how the surplus produce could be fully proportioned suggests that the potential production inputs nationally would conservatively be $1,116,000,000$ or about 1.1 billion pounds annually. Since there were 46.1 million SNAP recipients in May, 2015 [23] this data suggests that if all this category of food was used for new products, not including about 33\% already presumed donated, approximately 24 pounds could be served in meals or as products to each SNAP recipient each year. Not only will this added source help relieve chronic hunger; it will also help address the cost barriers that prevent these important sources of healthy dietary nutrients from reaching lower income people in the US. These general projections are for produce only, the possibilities for other foods, such as meats, grains, and dairy, to increase diversion of food waste to hunger relief only brightens this outlook.

\section{Summary and Conclusions}

In summary, the FSSM method looks at food loss and waste from the perspective of many stakeholders through a lens to optimize the balance between economic, social, and environmental benefits. Tools used with FSSM include: food waste tracking; geographic mapping and data base systems; recipe development; product potential, quality and safety; economic analysis; social needs assessment and capabilities; environmental impact analysis; business development; and education \& outreach. Based on our ongoing research into the fate of wholesome fruits and vegetables discarded from grocery stores we are encouraged that the economic opportunities may launch new methods to reduce all of the various impacts of food waste while creating new sources of healthy foods and jobs where both are in high demand. This represents an expanded sustainability model sensitive to new elements of the food system that are linking nutrition to social, economic, and environmental development. Fruits and vegetables are the immediate target of this research because this food is nutritious, fragile, likely to be discarded for cosmetic reasons alone, and represents about half of the U.S. Department of Agriculture's recom- 
mended daily meal [24].

Products that are under development at the Drexel Food Lab using surplus food are intentionally easy to prepare, preserving the natural health benefits of produce and minimizing the cost and labor associated with ingredients. It is this combination of surplus food and efficient recipes and processing that indicates that business opportunities may well be present in this area. With a conservatively estimated billion pounds of eatable produce lost each year, the quantity of supply is not an issue although the disbursed availability of surplus foods may narrow the possibilities for purely commercial uses. Food donations through charitable organizations will always be available while other elements of the EPA Food Recovery Hierarchy guide food waste management where the infrastructure for donation is not locally adequate.

This research builds upon the rapidly growing experience that is being developed by individuals in industry groups, academia, public institutions, and NGOs from around the world. Education and outreach are key elements of the FSSM method. Many of the steps in the process of sourcing surplus foods, preparing and testing recipes, and building product infrastructure are being digitally captured. The ability for widely educating interested people in the process using web-based, on-line courses is key to the partnership's vision and legacy. In addition to traditional means of information dissemination, we are building and creating digital documentation and training segments to help educate and teach vocational skills to people interested in solutions to the food waste problem that stress the environment, jobs, and health. These Targeted Open On-Line Courses are anticipated to provide the means for people to enter and contribute their own personal skills and expertise in a short time. Educating for sustainable food management at the professional-vocational level may rapidly scale food waste reduction at the community level. One of the early foundational videos designed to capture the essence of the problem and solutions can be viewed at www.servingfoodsolutions.com. Video development is the basis for new education and training e-learning modules that are referred to as targeted open-online courses (TOOC) by the World Food Forum reflecting the specificity of content and development for specific food system practitioners needing or wanting further training and certification for career advancement or life-long learning.

\section{Acknowledgements}

Disclaimer: Any views expressed in this report do not necessarily represent those of the United States government or the Environmental Protection Agency. Mention of trade names or commercial products does not constitute endorsement or recommendation for use.

\section{References}

[1] United Nations (2013) A New Global Partnership: Eradicate Poverty and Transform Economies through Sustainable Development. United Nations Publications, New York.

[2] Gustavsson, J., Cederberg, C., Sonesson, U., van Otterdijk, R. and Meybeck, A. (2011) Global Food Losses and Waste: Extent, Causes and Prevention. FAO, from Interpack2011, Düsseldorf, Germany. http://www.fao.org/docrep/014/mb060e/mb060e.pdf

[3] FAO (2013) Food Wastage Footprint: Impacts on Natural Resources (Summary Report). 1-63. http://www.fao.org/docrep/018/i3347e/i3347e.pdf

[4] Katz, S.H. (2012) The Future of Food. Part I: Food: Its Past, Present, and Future, American Philosophical Society Annual Walter L. Robb Symposium on "Useful Knowledge”, Philadelphia. http://diglib.amphilsoc.org/islandora/object/video\%3A1121

[5] Gunders, D. (2012) Wasted: How America Is Losing up to 40 Percent of Its Food from Farm to Fork to Landfill. Natural Resources Defense Council, IP:12-06-B. http://www.nrdc.org/food/wasted-food.asp

[6] United States Environmental Protection Agency (2014) Municipal Solid Waste Generation, Recycling, and Disposal in the United States, Tables and Figures for 2012, 63 p.

[7] HUD Exchange (2015) Promise Zone First Round Designees. http://tinyurl.com/mju8rme

[8] City of Philadelphia, January 8, 2014, City of Philadelphia Selected as a Promise Zone Designee.

[9] United States Department of Agriculture, 2015. http://www.ers.usda.gov/topics/food-nutrition-assistance/food-security-in-the-us/definitions-of-food-security.aspx

[10] United States Department of Agriculture, 2015. http://www.ers.usda.gov/topics/food-nutrition-assistance/food-security-in-the-us/key-statistics-graphics.aspx

[11] United States Environmental Protection Agency (2015) News Release from Region 3. http://tinyurl.com/n52bssd 
[12] Seymour, G., Tucker, G.A., Poole, M. and Giovannoni, J. (2013) The Molecular Biology and Biochemistry of Fruit Ripening. Wiley-Blackwell, Oxford. http://dx.doi.org/10.1002/9781118593714

[13] O’Donnell, T. (2014) Cobbler Cure-Doctor’s Orders. http://tinyurl.com/kxlss85

[14] Lampert, P. (2015) They Don’t Just Cook It, They Create It. http://www.supermarketguru.com/the-lempert-report/they-dont-just-cook-it,-they-create-it.html

[15] Huffington Post (2015) http://www.huffingtonpost.com/2015/03/02/drexel-food-lab-homeless_n_6784098.html

[16] Federal Executive Board (2015) http://tinyurl.com/lthelsc

[17] You Tube (2014) https://www.youtube.com/watch?v=31CYcEzaIKU

[18] Gunders, D. (2012) Wasted: How America Is Losing Up to 40 Percent of Its Food from Farm to Fork to Landfill. NRDC Issue Paper, iP:12-06-B.

[19] Buzby, J.C., Wells, H.F., Axtman, B. and Mickey, J. (2009) Supermarket Loss Estimates for Fresh Fruit, Vegetables, Meat, Poultry, and Seafood and Their Use in the ERS Loss-Adjusted Food Availability Data. Economic Information Bulletin No. (EIB-44), 26 p.

[20] Food Waste Reduction Alliance (2013) Grocery Stores and Food Waste.

http://www.foodwastealliance.org/wp-content/uploads/2013/05/FMI_food_waste_infographic-RETAILERS1.jpg

[21] United States Environmental Protection Agency (2015) http://epa.gov/epawaste/conserve/tools/warm/pdfs/Food Waste.pdf

[22] Food Marketing Institute (2015) http://www.fmi.org/research-resources/supermarket-facts

[23] United States Department of Agriculture (2015)

http://www.fns.usda.gov/pd/supplemental-nutrition-assistance-program-snap

[24] United States Department of Agriculture (2015) http://www.choosemyplate.gov/ 